\title{
LIBERDADE DE CULTO E O SACRIFÍCIO DE ANIMAIS EM CERIMÔNIAS RELIGIOSAS AFRO-BRASILEIRAS: UMA ANÁLISE À LUZ DA CONSTITUIÇÃO DO BRASIL
}

\author{
FREEDOM OF WORSHIP AND ANIMAL SACRIFICE RITUALS IN AFRO-BRAZILIAN \\ RELIGIONS: AN ANALYSIS UNDER THE BRAZILIAN CONSTITUTION
}

Augusto César Leite de Resende

\begin{abstract}
Doutorando em Direito pela PUCRS. Mestre em Direito pela PUCPR Especialista em Direito Público pela UNISUL Professor de Direito Constitucional da FANESE Promotor de Justiça em Sergipe. E-mail:augusto@mpse.mp.br
\end{abstract}

Recebido em: 25/08/2017

Aprovado em: 25/12/2017

RESUMO: A Constituição Federal de 1988 tutela igualmente o direito à liberdade religiosa e o direito ao meio ambiente sadio, protege a fauna e a flora, veda a realização de práticas que coloquem em risco sua função ecológica, que provoquem a extinção de espécies ou submetam os animais a crueldade e reconhece ainda o valor intrínseco dos elementos não humanos da biodiversidade. Assim, a questão envolvendo o sacrifício de animais nas cerimônias religiosas de matriz africana se apresenta como um hard case, na medida em que inexiste regra jurídica clara que estabeleça a solução para o conflito entre a liberdade religiosa e a proteção dos animais, o que impede, por consequência, uma reflexão sobre o tema na perspectiva da lógica do "tudo ou nada". Diante desse quadro, o presente artigo científico tem objetivo precípuo propor uma resposta constitucionalmente adequada acerca da possibilidade de sacrifício de animais nos cultos religiosos afro-brasileiros. Em relação ao procedimento metodológico, adotou-se o método dedutivo, para realizar uma pesquisa de cunho exploratório, descritivo e bibliográfico.

Palavras-chave: liberdade religiosa. proteção da biodiversidade. sacrifício de animais. religiões afro-brasileiras.

ABSTRACT: The Federal Constitution of 1988 trusteeship also the right to religious freedom and the right to a healthy environment, protect fauna and flora, prohibits the realization of practices that jeopardize their ecological function, causing the extinction of species or subject animal cruelty and recognizes the intrinsic value of nonhuman elements of biodiversity. So the question involving animal sacrifice in religious ceremonies of African origin is presented as a hard case, in that it does not exist clear legal rule providing the solution to the conflict between religious freedom and the protection of animals, which prevents therefore, a reflection on the topic from the perspective of the logic of "all-or-nothing-fashion". Thus, this article aims to propose, from a deductive, doctrinal and legislative research, a constitutionally adequate answer about whether or not the sacrifice of animals rituals in the afro-brazilian religions. Regarding the methodological procedure, the deductive method was adopted to carry out an exploratory, descriptive and bibliographic research.

Keywords: religious freedom. biodiversity protection. animal sacrifice. afro-brazilian religions. 
SUMÁRIO: 1. Introdução; 2. Direito fundamental à liberdade religiosa; 3. A proteção da biodiversidade na ordem jurídica brasileira; 4. A resposta constitucionalmente mais adequada ao hard case; Conclusão; Referências.

\section{Introdução}

O objetivo central deste artigo científico é analisar, à luz do direito constitucional brasileiro, a possibilidade ou não do sacrifício de animais nos cultos religiosos de matriz afrobrasileira, na medida em que a Constituição tutela igualmente o direito à liberdade religiosa e o direito ao meio ambiente sadio. A Lei Maior, de igual modo, protege a fauna e a flora, veda a realização de práticas que coloquem em risco sua função ecológica ou submetam os animais a crueldade, além de reconhecer o valor intrínseco dos elementos não humanos da biodiversidade.

Partir-se-á da premissa de que o abate de animais nas cerimônias religiosas de origem africana se apresenta como um hard case, na medida em que inexiste regra jurídica clara que estabeleça a solução para o caso, o que impede, por consequência, uma abordagem na perspectiva da lógica do "tudo ou nada". Por isso, com base em argumentos de princípios, propor-se-á, a partir de uma pesquisa dedutiva e bibliográfica, uma resposta adequada à Constituição para o conflito entre a liberdade de culto e a proteção dos animais.

Para tanto, refletir-se-á sobre o direito fundamental à liberdade religiosa e o seu exercício pelos praticantes das religiões de matriz africana no Brasil. Em seguida, discutir-se-á acerca da proteção internacional e constitucional da biodiversidade, especialmente $o$ reconhecimento normativo do valor intrínseco dos componentes da fauna e da flora e a proibição do emprego de meios cruéis para o abate de animais. Por fim, apontar-se-á qual a resposta constitucionalmente mais adequada ao caso envolvendo o sacrifício de animais nos rituais religiosos afro-brasileiros.

\section{Direito fundamental à liberdade religiosa}

A Constituição Federal reservou inteiramente o Título II aos Direitos e Garantias Fundamentais, nele positivando um leque amplo e extenso de direitos fundamentais do ser humano, classificando-os em cinco espécies, a saber: a) direitos e deveres individuais; b) direitos e deveres coletivos; c) direitos sociais; d) direitos à nacionalidade e e) direitos políticos.

No entanto, o rol do referido Título II da Carta Magna não é taxativo. Os direitos fundamentais não são apenas aqueles consagrados e reconhecidos formalmente na Constituição, pois a Carta Magna admite a existência de outros direitos fundamentais não inseridos no rol do Título II, reconhecendo, destarte, a existência dos chamados direitos materialmente fundamentais.

Os direitos fundamentais podem ser classificados em: direitos formalmente fundamentais e direitos materialmente fundamentais. Serão formalmente fundamentais, os direitos expressamente incorporados no catálogo dos direitos fundamentais da Constituição, independentemente de seu conteúdo (ALEXY, 2008). Por sua vez, os direitos materialmente fundamentais poderão ser identificados a partir do conceito aberto de direitos fundamentais adotado pelo art. $5^{\circ}, \S 2^{\circ}$, da Constituição Federal, pois possibilita o reconhecimento de direitos fundamentais positivados em outras partes do texto constitucional ou em tratados internacionais e até mesmo na identificação de direitos fundamentais não-escritos ou implícitos na Constituição, que sejam decorrentes do regime e princípios por ela adotados (SARLET, 2015).

A identificação e a caracterização de um direito materialmente dotado de fundamentalidade não são tarefas fáceis para o intérprete e aplicador do direito, pois não decorrem apenas da simples leitura do texto constitucional, na medida em que poderão, como 
visto alhures, existir outros direitos fundamentais dispersos no corpo da Constituição, positivados em tratados internacionais ou consagrados em princípios não assentados na Carta Magna.

A definição de direito fundamental, proposta por Ingo Wolfgang Sarlet (2015), permite ao intérprete a identificação e, consequentemente, a efetivação e a proteção de direitos fundamentais exclusivamente materiais, isto é, não consagrados expressamente no catálogo do Título II da Constituição Federal.

Assim, reconhecem-se direitos que, apesar de não positivados formalmente no rol do Título II da Constituição Federal, por seu conteúdo, importância e significado, podem ser considerados fundamentais e, por isso mesmo, inseridos na Carta Constitucional, produzindo todos os efeitos jurídicos como se direitos formalmente fundamentais fossem.

A dignidade da pessoa humana não é, ela mesma, um direito fundamental (SARLET, 2012), mas, enquanto princípio fundamental do Estado brasileiro, é a fonte e o fundamento dos direitos fundamentais e dos direitos humanos (SARLET, 2012), atuando, portanto, como critério de identificação de direitos materialmente fundamentais eventualmente existentes na ordem jurídica do Brasil. E nesse contexto, é possível afirmar que a liberdade religiosa, manifestada pela liberdade de crença e pela liberdade de culto, é direito, material e formalmente, fundamental positivado na ordem jurídica brasileira.

As liberdades de culto e de crença, como direitos formalmente fundamentais, estão expressamente positivadas no art. $5^{\circ}$, inciso VI, da Constituição Federal, que assim dispõe: "é inviolável a liberdade de consciência e de crença, sendo assegurado o livre exercício dos cultos religiosos e garantida, na forma da lei, a proteção aos locais de culto e a suas liturgias". São, igualmente, direitos materialmente fundamentais, pois diretamente fundados na dignidade humana.

A autonomia, na acepção kantiana, significa "não escolher de outro modo senão de tal modo que as máximas de sua vontade também estejam compreendidas ao mesmo tempo como lei universal no mesmo querer" (KANT, 2009, p. 285). A autonomia e a dignidade estão intrinsecamente relacionadas e mutuamente imbricadas porque a dignidade pode ser considerada como o próprio limite do exercício da autonomia, ao passo que este não pode ser exercido sem o mínimo de competência ética (WEBER, 2009). A partir de tal constatação, verifica-se que a autonomia e a autodeterminação de cada pessoa são elementos centrais da dignidade humana, de modo que as pessoas somente são autônomas e, portanto, dotadas de dignidade, quando definem as regras universais que regerão as suas vidas (SARLET, 2012).

A dignidade humana é o fundamento do livre arbítrio dos indivíduos, consistente na liberdade de buscar, à sua própria maneira, a felicidade e o ideal de viver bem (BARROSO, 2013a), porquanto o reconhecimento e a garantia dos direitos de liberdade constituem uma de suas principais exigências (SARLET, 2013). Nesse sentido, o princípio da dignidade humana é o alicerce da liberdade de escolha da religião ou seita religiosa, da liberdade de mudar de religião, da liberdade de descrença e da liberdade de manifestação exterior da fé.

A liberdade religiosa, que se desdobra na liberdade de crença, na liberdade de culto e na liberdade de organização religiosa (MORAIS, 2011), garante ao sujeito o direito à livre adoção de crença em valores transcendentais; de seguir dogmas baseados na fé e não na racionalidade estrita (TAVARES, 2008). Já a liberdade da liturgia, do culto propriamente dito, inclui um aspecto individual, e dos locais de sua prática; o direito de não ser inquirido pelo Poder Público sobre suas convicções e de não ser prejudicado, de qualquer forma, nas suas relações particularmente com o Estado, em virtude de sua crença declarada (TAVARES, 2008).

$\mathrm{O}$ direito à liberdade religiosa confere ao seu titular a liberdade de adotar, escolher, fazer proselitismo ou não de uma religião (CANOTILHO; MOREIRA, 2007). A liberdade de culto significa, por sua vez, a livre manifestação exterior da crença, pela prática de rituais e cerimônias próprios da religião (LEITE, 2014), vale dizer, guarda relação com os ritos, locais e outros 
aspectos essenciais ao exercício da liberdade de religião (SARLET; MARINONI; MITIDIERO, 2015). Enfim,

O direito à liberdade religiosa, uma das espécies do gênero direito fundamental à liberdade, consiste na possibilidade de livre escolha pelo indivíduo da sua orientação religiosa, porém, não se esgota no plano da crença individual, meramente subjetiva, de foro íntimo, e sim, abarca a prática religiosa, também denominada de liberdade de culto (OUFELLA; ELY, 2011, p. 441).

Os direitos humanos e os direitos fundamentais, sejam eles direitos de primeira, segunda ou terceira dimensão, inclusive as liberdades de crença, de religião e de culto, implicam para o Poder Público as obrigações constitucionais e convencionais, a saber: a) de respeitar o direito, ou seja, de não os violar, através de sua conduta; b) de protegê-los das agressões de terceiros e c) de satisfazê-los, cujos casos de violações decorrem, como regra, de omissões da Administração Pública (ABRAMOVICH; COURTIS, 2004).

$\mathrm{O}$ direito à liberdade religiosa em sentido lato se dirige, primordialmente, contra o Estado, que não pode impor uma religião oficial aos indivíduos, ou seja, não pode se intrometer indevidamente nas crenças das pessoas, do mesmo modo que não pode prescrever ou proibir uma crença ou religião. O indivíduo tem o direito de crer e não crer, de manifestar o credo e de viver segundo a sua própria convicção religiosa, sem ser molestado pelo Leviatã em razão de sua fé.

Por outro lado, as religiões afro-brasileiras celebram a divindade mediante cerimônias que envolvem o abate de animais, ultrapassando, portanto, a esfera meramente individual, na medida em que os seus rituais expressam a crença de forma a atingir um bem constitucionalmente tutelado que é a proteção à fauna. Tem-se, portanto, claro conflito entre a liberdade religiosa e a proteção dos animais, cuja solução não pode ser alcançada pela lógica do "tudo ou nada".

\section{A proteção da biodiversidade na ordem jurídica brasileira}

Com o fim da Segunda Guerra Mundial e o fim do nazismo, tem-se a emergência do processo de valorização da dignidade da pessoa humana e, por via de consequência, a reconstrução dos direitos humanos, como paradigma e referencial ético a orientar a ordem internacional (PIOVESAN, 2015), cujas expressões máximas foram a Declaração Universal dos Direitos Humanos de 1948, o Pacto Internacional dos Direitos Civis e Políticos e o Pacto Internacional dos Direitos Econômicos, Sociais e Culturais.

A visão inicial do direito internacional em relação à natureza era totalmente antropocêntrica porque não havia qualquer preocupação com a proteção do meio ambiente. Após a Segunda Guerra Mundial, porém, a globalização, o desenvolvimento econômico e o avanço tecnológico intensificaram o processo de degradação da biosfera de forma irresistível, colocando em risco o equilíbrio ecológico e, com isso, a existência da humanidade e da vida no planeta (MORIN, 2013).

Até os anos 1960, prevaleceu o antropocentrismo, em que o meio ambiente é protegido com o objetivo precípuo de assegurar o bem-estar do homem, num sentido utilitarista, partindo-se do pressuposto de que a natureza pode ser subjugada em favor dos interesses humanos (CHALFUN, 2010). Em 1962, Rachel Carson chamou a atenção do mundo para uma série de problemas ambientais decorrentes dos avanços tecnológicos e industriais empreendidos pelo homem após a Segunda Guerra Mundial. Em sua obra Silent Spring, relatou os efeitos nocivos ao meio ambiente e à saúde humana em virtude do uso crescente e indiscriminado de inseticidas e herbicidas, em especial o Dicloro-Difenil-Tricloroetano, conhecido como DDT, provocando comoção e indignação nos Estados Unidos da América e no resto do mundo (SAMPAIO, 2012). 
Com isso, a tomada de consciência a respeito do problema ambiental, antes restrito ao debate científico, ultrapassou, com o passar dos anos, as fronteiras da comunidade acadêmica e alcançou a sociedade civil, despertando a preocupação mundial com a crise ambiental que afeta a vida dos animais, das plantas e dos seres humanos, especialmente a partir dos anos de 1970, com o surgimento dos movimentos verdes como o conservacionista, o preservacionista, o antropocentrismo alargado, a ecologia profunda e o ecossocialismo ou ecomarxismo. Isso possibilitou uma discussão mundial mais ampla sobre o problema do crescimento econômico ilimitado inerente ao capitalismo, cujo ponto máximo ou divisor de águas foi a Conferência de Estocolmo de 1972 sobre o meio ambiente.

A Declaração de Estocolmo serve de paradigma e referencial ético à sociedade internacional, no que se refere à proteção internacional do meio ambiente como direito humano (SCHMIDT, 2010), posto que influenciou o reconhecimento do direito ao meio ambiente ecologicamente equilibrado como um direito humano entre os direitos sociais do homem por diversas Constituições nacionais, tratados internacionais de direitos humanos, dentre os quais a Convenção sobre Diversidade Biológica, e instrumentos de soft law (BOSSELMANN, 2010).

$\mathrm{O}$ regime de proteção internacional do meio ambiente tem, assim, a sua origem em particular, não no direito dos tratados, mas em conferências internacionais e em documentos de soft law, uma vez que a questão ambiental não estava na pauta dos interesses econômicos e políticos dos Estados, mas era sim objeto das preocupações científicas com o futuro da humanidade (BOSSELMANN, 2010).

No início dos anos 1990 a preocupação da comunidade internacional se volta para a preservação da natureza em seu conjunto e não mais unicamente das partes isoladas do meio ambiente porque "as vias para se responder à ameaça ecológica não são apenas técnicas; elas necessitam, prioritariamente, de uma reforma do nosso modo de pensar para englobar a relação entre humanidade e a natureza em sua complexidade" (MORIN, 2013, p. 104).

$\mathrm{O}$ direito internacional, diante da necessidade de mudanças de paradigmas e de percepção da relação do homem com a natureza, isto é, na forma de pensar os valores humanos, impôs, através da Convenção da Diversidade Biológica - $\mathrm{CDB}$, a proteção e a promoção da variedade de vida na Terra, consagrando na ordem jurídica mundial uma visão holística do mundo, no sentido de que os seres humanos e os demais elementos da natureza estão interligados e são interdependentes.

A Convenção da Biodiversidade tem, nos termos de seu art. $1^{\circ}$, como objetivo precípuo a conservação da diversidade biológica, definida pela própria Convenção, em seu artigo $2^{\circ}$, como a variabilidade de organismos vivos de todas as origens, compreendendo, dentre outros, os ecossistemas terrestres, aquáticos e os complexos ecológicos de que fazem parte; bem como a diversidade dentro de espécies, entre espécies e de ecossistemas.

Nessa esteira, como destacam Márcia Rodrigues Bertoldi e Karyna Batista Sposato (2012), a biodiversidade é "a vida sobre a terra". O seu conceito compreende a diversidade de espécies da fauna, da flora e de micro-organismos, a diversidade de ecossistemas e a diversidade genética dentro de cada espécie.

A Terra, de fato, é um organismo vivo. Os seres vivos, humanos e não humanos, o ar, o solo e os recursos hídricos formam a própria natureza, que funciona num todo. As partes que a compõem são interdependentes e inter-relacionadas e a interferência em um determinado componente de um ecossistema gera desequilíbrio para os demais, razão pela qual se impõe a respectiva preservação da integridade e equilíbrio (BECKERT, 2003).

Desse modo, a Convenção da Diversidade Biológica é importante instrumento jurídico que obriga a preservação da biodiversidade para a evolução e a manutenção dos sistemas necessários à vida no planeta, pois, como adverte Christian Lévêque (1999), a proteção da biodiversidade é indispensável para manter os processos do mundo vivo, já que ela promove a regulação dos equilíbrios físico-quimícos da biosfera. 
Os seres vivos são membros de comunidades ecológicas inter-relacionadas e interdependentes e portadores de igual consideração moral, de modo que se deve promover a preservação da vida e não a sua destruição. Assim, os valores morais são inerentes a todos os seres vivos porque os seres humanos e os não humanos são constitutivos de um todo só, a chamada teia da vida (CAPRA, 2006).

Ademais, o preâmbulo da Convenção da Diversidade Biológica reconhece expressamente que toda a vida tem um valor intrínseco, independentemente da utilidade que tenha para os seres humanos, pois a Terra é um verdadeiro ser vivo plenamente integrado por todas as formas de vida, interligados e interdependentes. A Terra apresenta-se, assim, como um todo, maior do que a soma de suas partes.

O direito internacional, ao consagrar o valor intrínseco dos elementos não humanos da natureza, ainda que no preâmbulo da Convenção da Biodiversidade, reconhece que o ser humano não ocupa uma posição superior ou privilegiada em relação aos demais elementos da natureza. Além disso, abraça a ideia de dignidade da própria vida de um modo geral e assegura a preservação de todas as formas de vida existentes no planeta, ainda que se possa admitir que a proteção da vida em geral constitua exigência da dimensão ecológica da dignidade da pessoa humana (SARLET, 2012).

A dignidade da pessoa humana não é excludente porque não eleva o homem à condição de senhor absoluto da natureza, mas sim inclusiva, pois dela decorrem deveres fundamentais de respeito e consideração com as demais formas de vida na Terra. A propósito, as lições de Ingo Wolfgang Sarlet (2012, p. 44):

[...] a dignidade da pessoa humana [...] há de ser compreendida como um conceito inclusivo, no sentido de que a sua aceitação não significa privilegiar a espécie humana acima das outras espécies, mas sim, aceitar que o reconhecimento da dignidade da pessoa humana resultam obrigações para com os outros seres e correspondentes deveres mínimos e análogos de proteção.

O valor intrínseco da diversidade biológica é princípio da comunidade internacional com forte conteúdo axiológico, de modo que, enquanto valor fundamental da ordem jurídica internacional, condiciona a compreensão e a interpretação dos textos normativos (ARONNE, 2013), inclusive internos.

A Convenção sobre Diversidade Biológica tem a natureza jurídica de tratado internacional de direitos humanos, na medida em que se destina, ainda que não exclusivamente, à proteção do indivíduo, diferenciando-se, por isso, dos tratados internacionais tradicionais, que são celebrados em benefício recíproco dos Estados pactuantes (ALCALÁ, 2015), e os seus preceitos são vinculativos e obrigatórios por parte dos Estados signatários (DONNELLY, 2013).

$\mathrm{Na}$ qualidade de tratado internacional de direitos humanos, a Convenção sobre Diversidade Biológica foi incorporada ao direito nacional como norma de valor constitucional ${ }^{1} \mathrm{e}$ integra a Constituição material brasileira, na medida em que a constitucionalização contemporânea do direito, fortemente influenciada pelo pós-positivismo, não se limita ao texto formal e expresso da Constituição, abarcando princípios implícitos e os tratados internacionais de direitos humanos (SCHIER, 2015), que passam a ser elementos integrantes da Constituição material, conceituada por José Joaquim Gomes Canotilho (2011, p. 1.139) como:

[...] o conjunto de fins e valores constitutivos do princípio efectivo da unidade e permanência de um ordenamento jurídico (dimensão objectiva), e o conjunto de

1 O Supremo Tribunal Federal reconhece, atualmente, a existência de tratados internacionais de direitos humanos supralegais, quando incorporados ao sistema jurídico brasileiro sem a observância dos requisitos descritos no $\S 3^{\circ}$ do art. $5^{\circ}$ da Carta Magna.

Revista de Direito Brasileira | São Paulo, SP | v. 20 | n. 8 | p. 287-304 |Mai./Ago. 2018 
forças políticas e sociais (dimensão subjectiva) que exprimem esses fins ou valores, assegurando a estes a respectiva prossecução e concretização, algumas vezes para além da própria constituição escrita. Ao contrário do que muitas vezes se pensa e vê escrito, a constituição material não se reconduz a um simples "poder de facto" ("relações de poder e influência", "facto político puro"), pois a constituição material tem também uma função ordenadora. A chamada força normativa de constituição (K. Hesse) pressupõe, a maior parte das vezes, a vontade de constituição, ou seja, a explicitação na constituição escrita ou formal do complexo de fins e valores agitados pelas constelações políticas e sociais a nível da constituição material.

A Constituição material é composta pelas normas relativas à estrutura do Estado, à organização dos poderes e aos direitos e garantias fundamentais (SARLET; MARINONI; MITIDIERO, 2015) e permite a abertura da Constituição a outros direitos fundamentais não elencados no Título II da Carta Magna e aos direitos humanos positivados em tratados internacionais.

A Constituição é um sistema aberto de regras e princípios (MIRANDA, 2011) que vai além da Constituição formal, fruto do poder constituinte, de modo a permitir a incorporação de princípios não escritos no texto constitucional. Ademais, a Carta Magna de 1988 reconhece expressamente, em seu art. $5^{\circ}, \S 2^{\circ}$, a existência de outras fontes do direito fora da própria Constituição (BARBOZA, 2014), o que possibilita a adoção pelo direito brasileiro de normas constitucionais não expressas no texto constitucional (BARBOZA, 2014).

As normas da Convenção sobre Diversidade Biológica integram, ainda que estejam fora do texto constitucional escrito, a Constituição material da República Federativa do Brasil. A existência de normas constitucionais situadas fora do texto formal da Constituição, a abarcar os tratados de direitos humanos, traduz um Direito em que o diálogo entre o direito interno e o direito internacional é inevitável (SCHIER, 2015).

Assim, o ordenamento jurídico brasileiro, a partir do diálogo com o direito internacional, reconhece que os componentes da diversidade biológica têm valor intrínseco, merecendo respeito e proteção independentemente do seu valor para o homem ou do potencial para uso humano, possibilitando assim a preservação da integridade do todo, de Gaia, da Terra.

A Convenção da Diversidade Biológica, logo, impõe à República Federativa do Brasil o reconhecimento do valor intrínseco de todos os elementos da biodiversidade e a obrigação de conservação e de utilização sustentável da diversidade biológica, que é de importância absoluta para atender as necessidades de alimentação física e espiritual e de saúde da crescente população mundial.

Além do mais, o art. 225, caput e inciso VII, do texto formal da Constituição Federal de 1988 consagra que "todos têm direito ao meio ecologicamente equilibrado", competindo ao Poder Público "proteger a fauna e a flora, vedadas, na forma da lei, as práticas que coloquem em risco sua função ecológica, provoquem a extinção de espécies ou submetam os animais a crueldade".

O ordenamento jurídico brasileiro tutela igualmente, como visto alhures, a liberdade religiosa e os elementos não humanos da biodiversidade. Assim, cabe indagar: o sacrifício de animais para efeitos de rituais religiosos é compatível com a Constituição Federal de 1988? É admissível a imposição de restrições à liberdade de culto das religiões afro-brasileiras em prol da proteção da natureza? Tais questões são altamente controversas para as quais não existe uma única resposta correta. 


\section{A resposta constitucionalmente mais adequada ao hard case}

No Estado liberal do século XIX, a lei era a fonte hegemônica do Direito e passou a ser o instrumento utilizado para aplicar e interpretar a Constituição, limitar o poder estatal e manifestar a vontade popular (MÖLLER, 2011), de maneira que o pensamento jurídico vigente até primeira metade do século XX, o positivismo jurídico, fundava-se na ideia da observância "cega" da lei, afastando do Direito a filosofia, os princípios, os valores e o sentido de Justiça (BARROSO, 2013b).

Os valores morais vigentes numa comunidade política não podiam ser, segundo o positivismo jurídico, levados em consideração pelo direito e pela ciência jurídica, uma vez que o conceito de direito era definido de modo a não incluir elementos morais (ALEXY, 2009). O direito deveria ser examinado e compreendido de modo distinto dos demais campos científicos.

Contudo, as concepções da infalibilidade do legislador, da lei como fonte única do Direito e de um ordenamento jurídico fechado e indiferente a valores éticos promoveram o fracasso político do positivismo jurídico. Já não mais se aceitava, passivamente, no pensamento jurídico do pós-guerra, tais ideias (BARROSO, 2013b). Por essa razão, o constitucionalismo mundial sofreu grandes e profundas transformações, dando margem ao surgimento do que se denominou de pós-positivismo e de neoconstitucionalismo, bem como o reconhecimento da força normativa da Constituição e dos princípios.

$\mathrm{O}$ Direito passa a compreender o valor normativo de regras e de princípios. $\mathrm{O}$ ordenamento jurídico é, a partir da segunda metade do século XX, entendido como um sistema íntegro de normas jurídicas, que tem como espécies princípios e regras (DWORKIN, 2010).

Além disso, o Direito deve ser compreendido e interpretado em sua unidade e integridade. E o princípio da integridade no direito orienta os juízes a identificar direitos legais a partir dos princípios existentes numa comunidade (DWORKIN, 2007). A esse respeito,

Segundo o direito como integridade, as proposições jurídicas são verdadeiras se constam, ou se derivam, dos princípios de justiça, equidade e devido processo legal que oferecem a melhor interpretação construtiva da prática jurídica (DWORKIN, 2007, p. 272).

E mais,

O direito como integridade pede que os juízes admitam, na medida do possível, que o direito é estruturado por um conjunto coerente de princípios sobre a justiça, a equidade e o devido processo legal adjetivo, e pede-lhes que os apliquem nos novos casos que se lhes apresentem, de tal modo que a situação de cada pessoa seja justa e equitativa segundo as mesmas normas (DWORKIN, 2007, p. 291).

Portanto, o direito como integridade parte da premissa de que o ordenamento jurídico é um sistema composto de regras e princípios. A propósito, ainda em companhia de Ronald Dworkin (2010, p. 39):

A diferença entre princípios jurídicos e regras jurídicas é de natureza lógica. Os dois conjuntos de padrões apontam para decisões particulares acerca da obrigação jurídica em circunstâncias específicas, mas distinguem-se quanto à natureza da orientação que oferecem. As regras são aplicáveis à maneira do tudo-ou-nada. Dados os fatos que uma regra estipula, então ou a regra é válida, e neste caso a resposta que ela fornece deve ser aceita, ou não é válida, e neste caso em nada contribui para a decisão. 
Para o autor norte-americano, as regras se aplicam por meio da subsunção. É dizer: se a regra é válida e estão presentes os pressupostos de fato que nela se subsumem, a regra deve ser aplicada. Os princípios são, por sua vez, padrões que devem ser observados, "não porque vá promover ou assegurar uma situação econômica, política ou social considerada desejável, mas porque é exigência de justiça ou equidade ou alguma outra dimensão da moralidade" (DWORKIN, 2010, p. 36).

A questão envolvendo o sacrifício de animais nas cerimônias religiosas de matriz africana se apresenta como um hard case, uma vez que inexiste regra jurídica clara que estabeleça a solução ou uma decisão em qualquer direção (DWORKIN, 2010), de modo que o Poder Judiciário deverá decidir o caso com base em princípios, confirmando ou negando direitos jurídicos preexistentes (DWORKIN, 2010).

A ausência de resposta inequívoca e previamente dada pela Constituição Federal de 1988 não confere aos magistrados absoluta discricionariedade decisória, devendo o juiz encontrar a melhor resposta possível ao caso concreto a partir de uma leitura construtiva da história, da tradição, dos precedentes e da moralidade política (MENDES, 2008). Os juízes deverão, destarte, decidir com fundamento em argumentos de princípio, entendidos estes como os destinados a estabelecer um direito aos indivíduos e não um objetivo coletivo (DWORKIN, 2010).

Como dito anteriormente, a Constituição tutela igualmente o direito à liberdade religiosa e o direito ao meio ambiente sadio. Nesse sentido, protege a fauna e a flora, vedando, inclusive, as práticas que coloquem em risco sua função ecológica, provoquem a extinção de espécies ou submetam os animais a crueldade e, por fim, reconhece o valor intrínseco dos elementos não humanos da biodiversidade. Nesse contexto, definir se é constitucionalmente possível ou não o sacrifício de animais nos cultos religiosos afro-brasileiros é um caso difícil e reclama para a sua solução a adoção de decisão judicial apoiada exclusivamente em princípios e "na consideração abstrata do indivíduo como sujeito moral” (MENDES, 2008, p. 38).

Não há, como se percebe, uma única resposta correta ao caso referente ao abate de animais em rituais religiosos, uma vez que os juízes poderão produzir decisões totalmente opostas que em tese se harmonizam com a estrutura da Constituição. Por isso, deve-se escolher a melhor resposta possível, que será aquela que consiga passar pelo duplo teste de adequação e de justiça (DWORKIN, 2007).

$\mathrm{O}$ teste da adequação exige que os juízes e tribunais decidam com base na ideia de romance em cadeia, "o juiz deverá encontrar a solução compatível com a experiência constitucional, com a história e seus precedentes" (MENDES, 2008, p. 46). A esse respeito, invocam-se as lições de Vera Karam de Chueiri (1995, p. 98):

A ideia da qual se parte é a da chain of law que, analogamente ao exercício literário de construção de um romance, pretende edificar uma decisão jurídica. Assim os juízes deveriam encarar a sua decisão (ato de criação) como um capítulo a mais de uma história já iniciada por outros e, portanto, levar em conta o que já foi escrito (ato de interpretação), no sentido de não romper com a unidade e coerência da história. Cada juiz (ou escritor) deve fazer da sua decisão (ou texto), naquele momento, a (ou o) melhor possível.

Como registra Conrado Hübner Mendes (2008), a interpretação deverá passar pelo segundo teste, o teste da justiça, onde o juiz deverá adotar, dentre as respostas possíveis, aquela que melhor promova e proteja os direitos fundamentais das pessoas, apresentando, para tanto, os argumentos de princípios justificadores de que essa foi a melhor resposta.

$\mathrm{O}$ direito à liberdade de crença ou religião e o direito à liberdade de culto não são direitos absolutos. Porém, enquanto direitos de hierarquia constitucional, somente podem ser restringidos ou mitigados por normas de hierarquia constitucional ou em virtude delas (ALEXY, 2008). 
Os direitos fundamentais podem ser limitados e restringidos em caráter geral por normas constitucionais ou, excepcionalmente, normas infraconstitucionais, desde que sua criação seja autorizada pela própria Constituição. Daí falar-se em restrições diretamente constitucionais, quando provenientes de normas de estatura constitucional, e em restrições indiretamente constitucionais, quando a Constituição permite a edição de normas infraconstitucionais restritivas de direitos fundamentais. Trata-se de uma espécie de zona de proteção formal dos direitos fundamentais, isto é, de limite formal à atividade restritiva desses direitos.

Os direitos fundamentais também podem ser limitados por outros direitos fundamentais ou por bens constitucionalmente tutelados, independentemente de expressa autorização na Carta Magna para a restrição. Nesse caso, colisões entre direitos fundamentais ou conflitos entre esses direitos e outros bens constitucionais legitimam o estabelecimento de restrições a direitos fundamentais não submetidos a reserva constitucional expressa nesse sentido (NOVAIS, 2010).

Explica-se. Como antes enunciado, o âmbito de proteção dos direitos fundamentais não sujeitos a restrições normativas vai até o ponto em que permita um equilíbrio com outros direitos fundamentais ou bens constitucionalmente colidentes, admitindo-se, destarte, limitações a direitos fundamentais a partir de outros direitos fundamentais ou interesses protegidos pela Carta Constitucional, com o fito de manter a concordância prática entre os mesmos (PIEROTH; SCHLINK, 2012).

Os direitos humanos fundamentais visam resguardar a primazia da dignidade da pessoa humana cujos contornos são moldados pelas relações das pessoas com outros indivíduos. A convivência social torna inevitável o surgimento de situações de tensão ou a realização simultânea dos direitos fundamentais e de outros bens constitucionais ou valores comunitários. Assim, a autonomia de um indivíduo pode ser restringida por valores, costumes, bens, interesses e direitos de outras pessoas igualmente livres e merecedoras de idêntica consideração e respeito, isso com o objetivo precípuo de proteger os direitos, a dignidade de terceiros ou bens tutelados constitucionalmente (BARROSO, 2013a).

A dignidade da pessoa humana sujeita-se, em sendo contraposto à igual dignidade de terceiros, a uma necessária relativização (SARLET, 2012). E, em razão de a dignidade humana estar umbilicalmente ligada aos direitos humanos e aos direitos fundamentais, quando dois ou mais direitos entram concretamente em conflito ou colidem com bens constitucionalmente tutelados, é mister e legítimo o estabelecimento de restrições ao seu exercício como forma necessária de compatibilização entre os direitos e bens colidentes.

O princípio da unidade da Constituição impõe o dever de compatibilização dos direitos, bens e valores em conflito, caso não seja possível a satisfação integral das normas em choque, admitindo-se, nesse caso, a restrição, ainda que não expressamente autorizada pela Carta Magna, aos direitos fundamentais e aos bens constitucionais em colisão (NOVAIS, 2010).

É o que ocorre entre o direito à liberdade religiosa e a proteção dos animais, que é, reitere-se, um bem constitucionalmente valioso e protegido, na medida em que nos rituais das religiões afro-brasileiras há o sacrifício de animais. Nesse caso, "as limitações impostas à liberdade de culto deverão decorrer de uma interpretação sistemática do texto constitucional" (LEITE, 2014, p. 315).

Para a solução do caso de sacrifício de animais durante as cerimônias religiosas de matriz africana, deve-se ter em consideração que a restrição a direitos fundamentais, no caso a liberdade religiosa, somente se dá de modo condicionado a determinados limites, cuja previsão tem como causa primeira a necessidade de proteger a eficácia dos direitos da atividade erosiva do Estado (TRAVINCAS, 2010, p. 4.688). Em suma, há limites aos limites dos direitos humanos e dos direitos fundamentais.

O controle das restrições de tais direitos por meio da imposição de limites é consequência do efeito recíproco dos direitos humanos e dos direitos fundamentais sobre os órgãos estatais: ao mesmo tempo em que lhes cabe restringir a área de proteção dos direitos, 
devem fazê-lo de modo a preservar ao máximo o direito restringido (TRAVINCAS, 2010, p. 4.688). Nesse contexto, a restrição a direitos fundamentais somente será legítima se observados os princípios da proporcionalidade e da proteção do conteúdo essencial deles, considerados verdadeiros limites materiais à atividade restritiva de direitos, especialmente quando a limitação decorrer de conflito entre eles.

A restrição de direitos humanos e de direitos fundamentais deve observar o chamado princípio da proteção do núcleo essencial, que se destina "a evitar o esvaziamento do conteúdo do direito fundamental decorrente de restrições descabidas, desmesuradas ou desproporcionais" (MENDES; BRANCO, 2013, p. 212), no qual o núcleo essencial de um direito humano ou de um direito fundamental seria aquele mínimo insuscetível de limitação.

No caso das religiões de matriz africana a crença e o culto são inseparáveis (MOFOKENG, 2007), vale dizer, a liberdade de crença e a liberdade de culto são indivisíveis, no sentido de que não se exerce o livre exercício de escolha de uma religião desvinculado da livre manifestação exterior da crença pela prática de atos próprios da religião.

Para a maioria das religiões africanas, o sangue e a vida estão umbilicalmente associados, de modo que o sacrifício de animais se tornou histórica e culturalmente um ritual inerente à maioria dessas religiões (BAKULUKI; MPYANGU, 2014). Na verdade, "o sacrifício é um fenômeno comum nas religiões afro-indígenas, nas práticas culturais e nas religiões dominantes convencionais. Constitui uma parte importante do culto, orações e ações de graças" (BAKULUKI; MPYANGU, 2014, p. 13, tradução nossa) ${ }^{2}$.

Os ritos são partes integrantes e inseparáveis da maioria das religiões de origem africana (BEYERS, 2010). A propósito:

As festas de candomblé, quando são realizadas as celebrações públicas de canto e dança, as chamadas cerimônias de barracão, durante as quais os orixás se manifestam por meio do transe ritual, são precedidas de uma série de ritos propiciatórios, que envolvem sacrifício de animais, preparo das carnes para o posterior banquete comunitário, fazimento das comidas rituais oferecidas aos orixás que estão sendo celebrados, cuidado com os membros da comunidade que estão recolhidos na clausura para o cumprimento de obrigações iniciáticas, preparação da festa pública e finalmente a realização da festa propriamente dita, ou seja, o chamado toque. Preparar o toque inclui cuidar das roupas, algumas costuradas especialmente para aquele dia, que devem ser lavadas, engomadas e passadas a ferro (é sempre uma enormidade de roupas para engomar e passar!); pôr em ordem os adereços, que devem ser limpos e polidos; preparar as comidas que serão servidas a todos os presentes e providenciar as bebidas; decorar o barracão, colhendo-se para isso as folhas e flores apropriadas etc (PRANDI, 2001, p. 45).

No que se refere ao abate de animais durante as cerimônias religiosas afro-brasileiras, vale ressaltar que:

Esta prática tem fundamentos milenares e mágicos além de representar um dogma para estas religiões. O sacrifício de animal é uma troca de energias entre o fiel e o animal quando este tem a finalidade de "descarregar" o fiel (tirar as energias negativas) neste caso o "carrego" passa do dele para o animal que é em seguida sacrificado. Existe ainda um outro tipo de sacrifício: o animal é sacrificado para o Orixá, o animal pode ser uma oferenda ao Orixá. Cada Orixá tem um animal que lhe pode ser ofertado; o pato, por exemplo, é um animal que

2 Sacrifice is a common phenomenon in the African indigenous religions, cultural practices as well as in the dominant - conventional religions. It constitutes an important part of worship, prayers and thanksgiving. (BAKULUKI; MPYANGU, 2014, p. 13). 
pode ser oferecido a Yemanjá. Em regra este tipo de oferenda é realizada uma vez por ano na festa do Orixá. Existem outros tipos de oferenda ao Orixá composta por flores e frutos e outros meios de descarregar uma pessoa, sempre que o sacrifício pode ser substituído por uma outra prática ele é mas existem situações em que o sacrifício se faz necessário e insubstituível pois este é da essência destas religiões. $O$ animal não é sacrificado por qualquer pessoa. Somente pode sacrificar um animal quem tem a "mão de faca" (a permissão dos Orixás para sacrificar um animal), em geral apenas o sacerdote tem esta permissão, porém, em alguns casos, pode-se encontrar outra pessoa dentro do "barracão" que o auxilie. Quando um sacerdote imola um animal, ele não está matando-o mais "entregando uma oferenda ao sagrado" (ROBERT, 2008, p. 02).

E mais,

Durante a matança, os orixás são consultados por meio do jogo oracular para se saber se estão satisfeitos com as oferendas, e podem pedir mais. De repente, então, é preciso parar tudo e sair para providenciar mais um cabrito, mais galinhas, mais frutas, ou seja lá o que for. Em qualquer dos momentos, orixás podem ser manifestar e será preciso cantar para eles, se não dançar com eles. Os orixás em transe podem, inclusive, impor alterações no ritual (PRANDI, 2001, p. 45).

Destarte, o sacrifício de animais deve ser considerado elemento essencial da religião propriamente dita e dos rituais religiosos africanos (POSSEBON, 2007), de modo que a sua proibição representará a aniquilação da religião em si e profundo ato de intolerância confessional e cultural em relação aos seus seguidores.

A cultura é o elemento identificador das sociedades humanas e engloba suas crenças e religiões (SOUZA FILHO, 2011). Com efeito, a cultura, entendida como "uma propriedade humana ímpar, baseada em uma forma simbólica, relacionada ao tempo, de comunicação, vida social, e a qualidade cumulativa de interação humana, permitindo que as ideias, a tecnologia e a cultura material se empilhem no interior dos grupos humanos" (MINTZ, 2010, p. 225), e a religião estão intimamente relacionadas.

A religião se baseia na fé que se manifesta na crença (SANCHES; SANTOS, 2013), que é "um elemento básico da realidade cognitiva humana, um ingrediente da vida, que permite aceitar ou não, defender ou não, reconhecer ou não, uma infinidade de elementos e situações do cotidiano" (SANCHES, 2010, p. 155) e recai sobre "elementos e situações que fogem do controle e do domínio pleno, mas perante os quais é preciso assumir uma atitude" (SANCHES, 2010, p. $155)$.

O homem, porém, conforme ensinam Mário Antônio Sanches e Renato Barbosa dos Santos (2013), aprende a crer em meio ao seu contexto cultural, pois é partir da cultura que se formam os conceitos religiosos. Nesse sentido, a religião é uma forma de expressão cultural (SANCHES; SANTOS, 2013), na medida em que "a cultura é onde a religião acontece, a religião está localizada dentro da cultura humana" (HEFNER, 2000, p. 91 apud SANCHES; SANTOS, 2013, p. 139) . $^{3}$.

Por isso, como dizem Mário Antônio Sanches e Renato Barbosa dos Santos (2013, p. 140), "cada cultura vive sua religião e dentro dela o ser humano se projeta rumo a uma busca que deverá culminar no encontro entre sua materialidade e sua transcendência" e "a religião como atividade cultural, busca dar sentido à existência de um povo, de uma cultura, projetando para além da simples materialidade de suas atitudes sendo essas atitudes boas ou ruins".

3 "Culture is where religion happens, religion is located within human culture" (HEFNER, 2000, p. 91).

Revista de Direito Brasileira | São Paulo, SP | v. 20 | n. 8 | p. 287-304 |Mai./Ago. 2018 
E se o meio ambiente natural é a garantia da sobrevivência física da humanidade, a cultura é a garantia de sobrevivência social dos povos porque produto e testemunho de sua vida. Assim, como assinala Carlos Frederico Marés de Souza Filho (2011, p. 16), "um povo sem cultura ou dela afastado, é como uma colmeia sem abelha rainha, um grupo sem norte, sem capacidade de escrever sua própria história e, portanto, sem condições de traçar o rumo de seu destino".

A proibição total do sacrifício de animais acarretaria, nesse contexto, a violação ao núcleo essencial do direito à liberdade de culto e ao do direito à liberdade de religião e de crença daqueles que professam a fé das religiões africanas e a destruição da própria cultura afrobrasileira expressada por meio do candomblé e da umbanda.

Por outro lado, deve-se promover a concordância prática entre os bens constitucionalmente tutelados, possibilitando concomitantemente a prática do ritual religioso e a proteção dos animais (SCHYFF, 2014), o que somente será alcançado se não forem utilizados animais em extinção e meios cruéis no ritual sacrificial ou que possam causar sofrimento excessivo aos animais (SCHYFF, 2014).

Os animais sacrificados nos rituais religiosos de matriz africana não estão ameaçados de extinção, sendo possível apontar, de acordo com o orixá ao qual se dirige a oferenda, que os animais abatidos são sempre animais domésticos, tais como bodes, cabras, carneiros, porcos, pombos, codornas, patos, frangos, galos e galinhas (LEITE, 2013). Além do mais, "estudos voltados às religiões de matriz africana, ao tratarem especificamente dos rituais de sacrifício de animais, não apontam práticas que poderiam ser caracterizadas como cruéis" (LEITE, 2013, p. 174), eis que "existe um cuidado especial para com os animais que serão sacralizados, pois o sacrifício deve ser realizado sem oferecer sofrimento para o animal" (COELHO; OLIVEIRA; LIMA, 2016, p. 60).

Portanto, o abate de animais em rituais religiosos afro-brasileiros não encontra vedação expressa na Constituição Federal e decorre da liberdade de culto e deve ser, por isso mesmo, respeitado, promovido e protegido pelo Poder Público, sem qualquer interferência estatal, desde que, repita-se, não sejam usados animais em extinção ou utilizados meios cruéis para o ritual sacrificial.

\section{Conclusão}

O objetivo central deste artigo científico foi analisar se é constitucionalmente possível ou não o sacrifício de animais nos cultos religiosos afro-brasileiros. Partiu-se da premissa que a questão envolvendo o abate de animais nas cerimônias religiosas de matriz africana se apresenta como um hard case, na medida em que inexiste regra jurídica clara que estabeleça a solução, mormente quando a Constituição tutela igualmente o direito à liberdade religiosa e o direito ao meio ambiente sadio, protege a fauna e a flora, vedando, inclusive, as práticas que coloquem em risco sua função ecológica, provoquem a extinção de espécies ou submetam os animais a crueldade e reconhece ainda o valor intrínseco dos elementos não humanos da biodiversidade.

O intérprete tem o dever de compatibilizar os direitos, os bens e os valores em conflito, caso não seja possível a satisfação integral das normas envolvidas, admitindo-se, nesse caso, a restrição, ainda que não expressamente autorizada pela Carta Magna, aos direitos fundamentais e aos bens constitucionais em colisão.

É o que ocorre entre o direito à liberdade religiosa e a proteção da fauna, que é um bem constitucionalmente valioso e protegido, na medida em que nos rituais das religiões afrobrasileiras há o sacrifício de animais.

Para a solução deste caso difícil, deve-se ter em consideração que a restrição ao direito fundamental à liberdade religiosa somente se dá de modo condicionado a determinados limites, cuja previsão tem como causa primeira a necessidade de proteger a eficácia dos direitos da 
atividade erosiva do Estado. Assim, a restrição de direitos deve observar o chamado núcleo essencial dos direitos fundamentais.

Nesse sentido, a proibição do sacrifício de animais em cerimônias religiosas representará, não somente violação do núcleo essencial do direito fundamental à liberdade religiosa, mas a aniquilação da própria religião afro-brasileira e profundo ato de intolerância confessional e cultural em relação aos seus seguidores, uma vez que o procedimento é considerado elemento essencial da religião em si e dos rituais religiosos africanos.

Por outro lado, deve-se promover a concordância prática entre os bens constitucionalmente tutelados, possibilitando concomitantemente a prática do ritual religioso e a proteção dos animais, o que somente será alcançado se não forem utilizados animais em extinção e meios cruéis no ritual sacrificial ou que possam causar sofrimento excessivo aos animais, o que não é o caso das religiões de matriz africana.

Assim, desde que não sejam utilizados animais em extinção ou empreendidos meios cruéis nas cerimônias confessionais africanas, é constitucionalmente possível o sacrifício de animais nos cultos religiosos afro-brasileiros sem qualquer interferência do Estado.

\section{Referências}

ABRAMOVICH, Víctor; COURTIS, Christian. Los derechos sociales como derechos exigibles. 2. ed.. Madrid: Trotta, 2004.

ALCALÁ, Humberto Nogueira. El diálogo interjurisdiccional y control de convencionalidad entre tribunales nacionales y Corte Interamericana de Derechos Humanos en Chile. In: SARLET, Ingo Wolfgang; GOMES, Eduardo Biacchi; STRAPAZZON, Carlos Luiz (Orgs.). Direitos humanos e fundamentais na América do Sul. Porto Alegre: Livraria do Advogado, 2015.

ALEXY, Robert. Conceito e validade do direito. São Paulo: WMF Martins Fontes, 2009.

Teoria dos direitos fundamentais. Tradução de Virgílio Afonso da Silva. São Paulo: Malheiros, 2008.

ARONNE, Ricardo. Sistema jurídico e unidade axiológica: os contornos metodológicos do direito civil constitucional. Revista do Instituto do Direito Brasileiro, Lisboa, Ano 2, n. 1, p. 73113, 2013.

BAKULUKI, Paul; MPYANGU, Christine Mbabazi. The african conception of sacrifice and its relationship with child sacrifice. International Letters of Social and Humanistic Sciences, Bäch, vol. 41, 2014, p. 12-24.

BARBOZA, Estefânia Maria de Queiroz. Precedentes judiciais e segurança jurídica: fundamentos e possibilidades para a jurisdição constitucional brasileira. São Paulo: Saraiva, 2014.

BARROSO, Luís Roberto. A dignidade da pessoa humana no direito constitucional: a construção de um conceito jurídico à luz da jurisprudência mundial. Belo Horizonte: Fórum, 2013.

- Curso de direito constitucional contemporâneo: os conceitos fundamentais e a construção do novo modelo. 4. ed.. São Paulo: Saraiva, 2013.

BECKERT, Cristina. Dilemas da ética ambiental: estudo de um caso. Revista Portuguesa de Filosofia, Lisboa, n. 59, 2003. 
BERTOLDI, Márcia Rodrigues; SPOSATO, Karyna Batista. Instrumentos de proteção dos conhecimentos tradicionais associados à biodiversidade. Revista de Direitos Fundamentais e Democracia, Curitiba, v. 12, n. 12, p. 75-93, julho/dezembro de 2012.

BEYERS, Jaco. What is religion? An african understanding. HTS - Teologiese Studies and Theological Studies, Durban, vol. 66, n. 1, p. 1-8.

BOSSELMANN, Klaus. Direitos humanos, meio ambiente e sustentabilidade. In: SARLET, Ingo Wolfgang (org.). Estado socioambiental e direitos fundamentais. Porto Alegre: Livraria do Advogado, 2010.

CANOTILHO, José Joaquim Gomes. Direito constitucional e teoria da Constituição.7. ed. Coimbra: Almedina, 2011.

CANOTILHO, José Joaquim Gomes; MOREIRA, Vital. Constituição da República Portuguesa Anotada, Vol. I, 4. ed.., Coimbra: Coimbra Editora, 2007.

CAPRA, Fritjof. A teia da vida: uma nova compreensão científica dos sistemas vivos. São Paulo: Cultrix, 2006.

CHALFUN, Mery. Paradigmas filosóficos - ambientais e os direitos dos animais. Revista Brasileira de Direito Animal. Salvador: Evolução, ano 5, vol. 6, p. 209-246, jan./jun. 2010.

CHUEIRI, Vera Karam de. Filosofia do direito e modernidade: Dworkin e a possibilidade de um discurso instituinte de direitos. Curitiba: J.M., 1995.

COELHO, Carla Jeane Helfemsteller; OLIVEIRA, Liziane Paixão Silva; LIMA, kellen Josephine Muniz de. Sacrifício ritual de animais não-humanos nas liturgias religiosas de matriz africana: "medo do feitiço" e intolerância religiosa na pauta legislativa. Revista Brasileira de Direito Animal, Salvador, v. 11, n. 22, p. 53-82, mai./ago. 2016.

DONNELLY, Jack. Universal human rights in theory and practice. 3. ed., New York: Cornell University Press, 2013.

DWORKIN, Ronald. Levando os direitos a sério. Tradução de Nélson Boeira. 3. ed.. São Paulo: WMF Martins Fontes, 2010.

Fontes, 2007.

O império do direito. Tradução de Jefferson Luiz Camargo. 2. ed.. São Paulo: Martins

HEFNER, Philip. Imago dei: the possibility and necessity of the human person. In: GREGERSEN, Niels Henrik; DREES, Willen B.; GÖRMAN, Ulf (ed.). The human person in science and theology.Edimburgo: T \& T Clark, 2000, p. 73-94 apud SANCHES, Mário Antônio; SANTOS, Renato Barbosa dos. Cultura e religião: suas peculiaridades e efeitos na parentalidade. III Jornada Interdisciplinar de Pesquisa em Teologia e Humanidades, Curitiba, vol. 3, n. 1, 2013, p. $137-145$.

KANT, Immanuel. Fundamentação da metafísica dos costumes. São Paulo: Discurso Editorial: Barcarolla, 2009. 
LEITE, Fábio Carvalho. Estado e religião: a liberdade religiosa no Brasil. Curitiba: Juruá, 2014. . A liberdade de crença e o sacrifício de animais em cultos religiosos. Revista Veredas do Direito, Belo Horizonte, vol. 10, n. 20, p. 163-177, jul./dez. 2013.

LÉVÊQUE, Christian. A biodiversidade. São Paulo: EDUSC, 1999.

MENDES, Conrado Hübner. Controle de constitucionalidade e democracia. Rio de Janeiro: Elsevier, 2008.

MENDES, Gilmar Ferreira; BRANCO, Paulo Gustavo Gonet. Curso de direito constitucional. 8. ed.. São Paulo: Saraiva, 2013.

MINTZ, Sidney W. Cultura: uma visão antropológica. Tempo, Niterói, vol. 14, n. 28, jan./jun. 2010.

MIRANDA, Jorge. Teoria do Estado e da Constituição.Rio de Janeiro: Forense, 2011.

MOFOKENG, Lesala L. The right to freedom of religion: an apparently misunderstood aspect legal diversity in South Africa. Law, Democracy \& Development Journal of the Faculty of Law, Cidade do Cabo, Vol. 11, N. 2, 2007, p. 121-131.

MÖLLER, Max. Teoria geral do neoconstitucionalismo: bases teóricas do constitucionalismo contemporâneo. Porto Alegre: Livraria do Advogado, 2011.

MORAIS, Márcio Eduardo Pedrosa. Religião e direitos fundamentais: o princípio da liberdade religiosa no Estado Constitucional Democrático brasileiro. Revista Brasileira de Direito Constitucional - RBDC, n. 18, jul./dez/ 2011.

MORIN, Edgar. A via para o futuro da humanidade. Rio de Janeiro: Bertrand Brasil, 2013.

NOVAIS, Jorge Reis. As restrições aos direitos fundamentais não expressamente autorizadas pela Constituição. 2. ed.. Coimbra: Wolters Kluwer: Coimbra Editora, 2010.

OUFELLA, Jociane Machiavelli; ELY, Pricila Carla da Silva. A influência do direito fundamental da liberdade de crença religiosa diante do fluxo migratório no Brasil: a busca pelo asilo. Revista de Direito Brasileira, vol. 1, n. 1, p. 423-451, 2011.

PIEROTH, Bodo; SCHLINK, Bernhard. Direitos fundamentais. Tradução de António Francisco de Sousa e António Franco. São Paulo: Saraiva, 2012.

PIOVESAN, Flávia. Direitos humanos e justiça internacional: um estudo comparativo dos sistemas regionais europeu, interamericano e africano. 6. ed.. São Paulo: Saraiva, 2015.

POSSEBON, Roberta Motim. A reação das religiões de matriz africana no Rio Grande do Sul: conflitos com neopentecostais e defensores dos animais, Rio Grande do Sul. 2007. 174f. Dissertação (Mestrado em Ciências Sociais). Faculdade de Filosofia e Ciências Humanas, Pontifícia Universidade Católica do Rio Grande do Sul, Porto Alegre. 
PRANDI, Reginaldo. O candomblé e o tempo: concepções de tempo, saber e autoridade da África para as religiões afro-brasileiras. Revista Brasileira de Ciências Sociais, São Paulo, vol. 16, n. 47, p. 43-58, outubro/2001.

ROBERT, Yannick Yves Andrade. Sacrifício de animais em rituais de matriz africanas. Disponível em: http://www.pucrio.br/Pibic/relatorio_resumo2008/relatorios/ccs/dir/yannick_yves_andrade_robert.pdf.

SAMPAIO, Rômulo Silveira da Rocha. Direito ambiental: doutrina e casos práticos. Rio de Janeiro: Elsevier: FGV, 2012.

SANCHES, Mário Antônio. Religião e ciência: o porquê do diálogo. In: ROSSI, Luiz Alexandre; KUZMA, César Solano (org.). Ciência, religião e sociedade: um diálogo entre diferentes saberes. Curitiba: Champagnat, 2010, p. 155-167.

SANCHES, Mário Antônio; SANTOS, Renato Barbosa dos. Cultura e religião: suas peculiaridades e efeitos na parentalidade. III Jornada Interdisciplinar de Pesquisa em Teologia e Humanidades, Curitiba, vol. 3, n. 1, 2013, p. 137-145.

SARLET, Ingo Wolfgang. A eficácia dos direitos fundamentais: uma teoria geral dos direitos fundamentais na perspectiva constitucional. 12. ed.. Porto Alegre: Livraria do Advogado, 2015.

Dignidade da pessoa humana e direitos fundamentais na Constituição Federal de 1988.

9. ed.. Porto Alegre: Livraria do Advogado, 2012.

As dimensões da dignidade da pessoa humana: construindo uma compreensão jurídicoconstitucional necessária e possível. In: SARLET, Ingo Wolfgang (org.). Dimensões da dignidade: ensaios de filosofia do direito e direito constitucional. 2. ed.. Porto Alegre: Livraria do Advogado, 2013.

SARLET, Ingo Wolfgang; MARINONI, Luiz Guilherme; MITIDIERO, Daniel. Curso de direito constitucional. 4. ed., São Paulo: Saraiva, 2015.

SCHIER, Paulo Ricardo. Filtragem constitucional e ADPF 138. Gazeta do Povo. Curitiba, 21 de dezembro de 2015. Disponível em: http://www.gazetadopovo.com.br/vida-publica/justica-edireito/artigos/filtragem-constitucional-e-adpf-378-1841mh3iwmui5eu9c76tn7ib9.

SCHMIDT, Rafael Vitória. Os direitos humanos e o direito internacional do meio ambiente. Revista Unoesc \& Ciência - ACSA.Joaçaba, v. 1, n. 1, p. 71-78, 2010.

SCHYFF, Gerhard Van Der. Ritual slaughter and religious freedom in a multilevel Europe: the wider importance of the dutch case. Oxford Journal of Law and Religion, vol. 3, n. 1, 2014, p. 76-102.

SOUZA FILHO, Carlos Frederico Marés de. Bens culturais e sua proteção jurídica. 3. Ed. Curitiba: Juruá, 2011.

TAVARES, André Ramos. Religião e neutralidade do Estado. Revista Brasileira de Estudos Constitucionais - RBEC, Belo Horizonte, ano 2, n. 5, p.13-25, jan./mar. 2008. Disponível em: http://www.bidforum.com.br/bid/PDI0006.aspx?pdiCntd=52587. 
TRAVINCAS, Amanda Costa Thomé. Procusto e o mito da forma: o conteúdo essencial como limite às restrições aos direitos fundamentais e o problema da redução da eficácia das normas. Anais do XIX Encontro Nacional do CONPEDI. Fortaleza: Fundação Boiteux, p. 4.677-4.702, 2010. Disponível em: http://www.publicadireito.com.br/conpedi/manaus/arquivos/anais/fortaleza/3962.pdf. Acesso em: 14 de junho de 2013.

WEBER, Thadeu. Autonomia e dignidade da pessoa humana em Kant. Revista Direitos Fundamentais \& Justiça, Porto Alegre, Ano 3, N. 9, out./dez. 2009, p. 232-259. 